\title{
Effects of training on equine muscle physiology and muscle adaptations in response to different training approaches
}

\author{
Fysiologische effecten van verschillende soorten arbeid op de \\ spierontwikkeling van het paard
}

\author{
${ }^{1}$ R. Vermeulen, ${ }^{1} \mathrm{C}$. de Meeûs, ${ }^{1} \mathrm{~L}$. Plancke, ${ }^{1} \mathrm{~B}$. Boshuizen, ${ }^{2} \mathrm{M}$. de Bruijn, ${ }^{1} \mathrm{C}$. Delesalle \\ ${ }^{1}$ Department of Comparative Physiology and Biometrics, Faculty of Veterinary Medicine, \\ Ghent University, Salisburylaan 133, B-Merelbeke, Belgium \\ ${ }^{2}$ Wolvega Equine Clinic, Stellingenweg 10, NL-8474-EA Oldeholtpade, the Netherlands
}

Catherine.Delesalle@UGent.be

\begin{abstract}
$\Lambda_{\text {bstract }}$
It is well known that exercise induces chemical, metabolic and structural changes in muscles. However, the effect of the type of exercise on these changes has not been thoroughly studied in horses yet, because of a lack of standardized study methods. In this review, the effect of three different types of exercise on muscle adaptation and metabolic responses is investigated. The requirements for power exercise are not the same as for low intensity exercise. Each type of training induces its own shift in muscle fiber typing, as well as in enzyme concentrations and (an) aerobic capacity. These physiological adaptations in response to training facilitate more efficient exercise and therefore increase performance. Hence, it is important to know the adaptations that muscles undergo in response to each type of exercise to optimize training management of sport horses in function of the needs of the discipline in which they compete.
\end{abstract}

\section{SAMENVATTING}

Het is algemeen bekend dat training leidt tot chemische, metabole en structurele veranderingen in spieren. De invloed van het type van training op deze veranderingen werd echter nog onvoldoende bestudeerd in paarden vanwege een gebrek aan gestandaardiseerde onderzoeksmethoden. In dit overzichtsartikel wordt het effect van drie soorten training op de spierevolutie en metabole veranderingen onderzocht. De vereisten voor powertraining verschillen van die voor (langdurige) inspanning van lage intensiteit. Elk type training leidt tot een specifieke shift van spiervezeltypes, enzymconcentraties en (an)aerobe capaciteit. Deze fysiologische adaptaties als gevolg van training faciliteren het uitvoeren van de specifieke inspanningen en verhogen zo de prestatie. Het kennen van deze adaptaties per type training kan helpen om de training en het management van sportpaarden te optimaliseren in functie van hun discipline.

\section{INTRODUCTION}

One of the ultimate goals of training an athlete, whether it is human or equine, is to modulate muscular physiology, since all power to perform exercise is eventually generated within these muscles. In human athletes, a plethora of controlled standardized studies has been performed, focusing on the different effects of different types of exercise on muscle metabolism and power output capacity. However, in horses, a lot still needs to be unraveled. The available equine studies often greatly differ in their approach (subjects of different breeds, ages, etc.), and the results are often expressed in different units, which makes comparison difficult. The aim of the current review is to map out the physiological response of the equine muscle in response to three different types of exercise, i.e. power exercise, intermediate intensity-duration exercise and stamina exercise, using standardized methods. This review aims to lay the foundation for future standardized studies.

\section{ANATOMY OF THE MUSCLE}

From a physiological point of view, there are four important structural entities within the muscle fiber: 1. Vascular supply to the muscle is especially impor- 
tant for the aerobic red slow twitch muscle fiber type, since efficient oxygen supply needs to be realized by muscle capillaries. 2 . The muscle cell membrane is a complex structure loaded with transport systems, such as GLUT 4 to shuttle different types of fuel into the muscle cell. 3. A complex set of intracellular organelles such as the endoplasmatic reticulum and mitochondria. They govern the use of different types of fuel within the muscle fiber to eventually generate adenosine-triphosphate (ATP), needed as the ultimate energy source for the muscle cell to induce a muscular contraction by 4 . the contractile elements actin and myosin (Clayton, 1991). In addition, there are three different types of muscle fibers (Table 1): 1 . slow twitch muscle fibers (type I), which are typically 'red' (lots of myoglobin needed for oxygen transport), lean and long (small diffusion distance for optimal oxygen transport), have a low glycogen storage capacity and an important aerobic capacity both with respect to aerobic glycolysis as with respect to aerobic lipolysis. 2. The fast twitch muscle fibers (type IIx), which are voluminous, white and have an important capacity to store glycogen because they mainly thrive on anaerobic glycolysis. The advantages of anaerobic glycolysis are that it can start up seconds after the onset of exercise, and no oxygen is needed. However, it is inefficient ( 3 moles of ATP are generated out of 1 to 2 moles of glucose versus 39 moles of ATP out of 1 mole of glucose in case of aerobic glycolysis). Lactic acid accumulation and rapid depletion of muscle glycogen, both consequences of anaerobic glycolysis, lead to (early) muscle fatigue. 3 . The third type of muscle fibers holds the middle between slow and fast twitch. Those are referred to as 'intermediate muscle fiber type' (type IIa). Imposing for example endurance training upon an equine athlete can stimulate transition of these intermediate fibers towards a more aerobic profile.

Human triathlon athletes are typically well-muscled and have a lean muscled appearance. Sprinter athletes, who are trained to have a lot of fast twitch explosive force muscle fibers, have a 'doubled muscled' appearance (Figure 1). In humans, the overall body composition slow versus fast twitch is almost fifty-fifty. In horses, the fast twitch fibers predominate, but the amount of slow twitch fibers depends on the horse breed. Quarter horses for example, which are typically used for short explosive type of exercise, are known to have approximately $45 \%$ fast twitch,

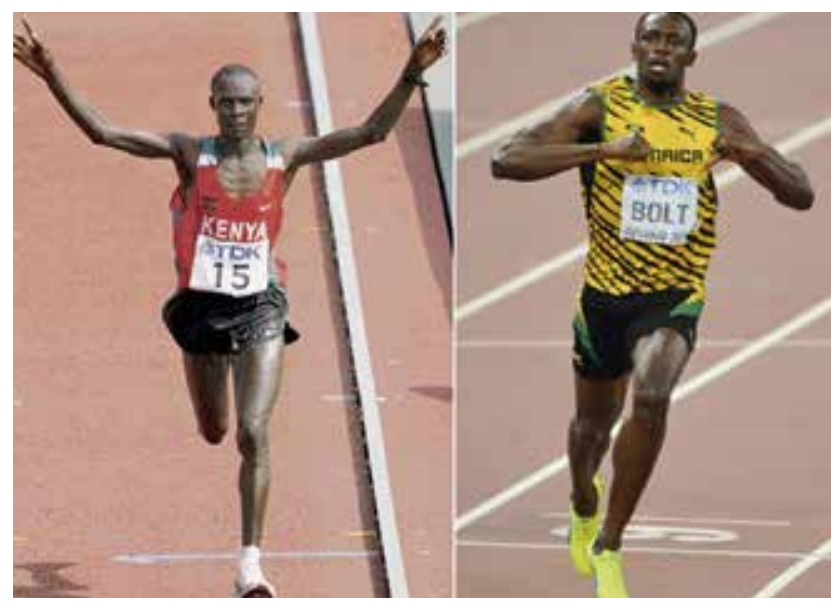

Figure 1. Differences in muscle appearance between endurance athletes and sprinters (Left Panel: endurance athlete Paul Tanui (source: https://citizentv.co.ke/ sports).; Right panel: sprint athlete Usain Bolt (source: http://www.erki.nl).

$48 \%$ intermediate twitch and 7\% slow twitch muscle fiber types (Snow et al., 1994). Rivero and Barrey (2001) have demonstrated that, even when all biopsied horses are of the same breed (purebred Spanish horse), interindividual variation in fiber type composition of the $\mathrm{m}$. gluteus medius remains high. Within the horse, the fiber composition also varies depending on the muscle and its function (Rivero and Hill, 2016). Muscle groups involved in the stay apparatus typically contain a lot of slow twitch fibers. Muscles in the hind limbs contain a higher percentage of fast twitch fibers than in the front limbs (Kawai et al., 2009). Finally, within the same muscle, fiber type composition changes with depth from the muscle surface. The superficial parts of equine muscles usually contain a higher percentage of fast twitch fibers than the deeper layers (Lopez-Rivero et al., 1992). Consequently, results of studies can only be compared when the same muscle groups have been biopsied at the same depth.

\section{MUSCLE PHYSIOLOGY DURING EXERCISE}

As mentioned previously, muscle fibers may use different types of fuel to create ATP, the energy-containing molecule necessary for muscle contraction. Which fuel is used to generate ATP depends upon the time point within the exercise episode (not all fuels

Table 1. Main properties of the three muscle fiber types.

\begin{tabular}{lll}
\hline Slow twitch (type I) & Intermediate fibers (type IIa) & Fast twitch (type IIx) \\
\hline Slow oxidative fibers & Fast oxidative fibers & Fast glycolytic fibers \\
Aerobic metabolism & Intermediate aerobic/anaerobic metabolism & Anaerobic metabolism \\
Long distance/low intensity sports & High myoglobin content & Power sports/ short distance \\
Fat accumulation & High glycogen content & Lactic acid producing metabolism \\
Low glycogen content & Highly adaptive to training & High glycogen content \\
Small diameter and red color & & Large diameter and white color \\
\hline
\end{tabular}


are immediately available), the intensity of the performed exercise and the 'preferred' fuel of the specific fiber type.

Typically, at the start of any exercise, all ATP that is present within the muscle will be used. This provides enough energy for only fractions of seconds. In a second step, the creatine phosphate pathway is activated. This typically is the 'start-up' motor of exercise. It is called the intermediate metabolism, since it doesn't need oxygen (anaerobic), and on top of that, no lactic acid is produced. The advantage is that the muscle uses creatine phosphate instead of glycogen at that point to perform swift and explosive exercise, which has a glycogen sparing effect. Certain types of training can increase creatine phosphate reserves inside the muscles of human athletes (Buford et al., 2007; MacDougall et al., 1977). In horses, no controlled studies are available. Some studies have looked into the effect of oral creatine supplementation in horses on muscular creatine phosphate reserves, but without any effect. This has been attributed to low creatine oral bioavailability in horses (Schuback et al., 2000).

A few seconds after the onset of exercise, anaerobic glycolysis starts up. Anaerobic metabolism covers the oxygen-independent pathways. The major energy sources are muscle and liver glycogen. It is very fast but relatively inefficient: muscle glycogen depletion and lactic acid accumulation are the limiting factors. Anaerobic metabolism is perfectly fit for high power or sprint exercise. When a horse is to perform exercise at an intensity above its aerobic capacity, this anaerobic motor remains active until exhaustion occurs.

Only two to three minutes after the onset of exercise, the aerobic glycolysis starts up and allows for production of large amounts of ATP without lactic acid production. Aerobic metabolism is a slow process but highly fatigue-resistant. This metabolism uses either carbohydrates (early stage) or fatty acids (as of thirty minutes after the start of exercise, at least in humans) (Rivero, 2007). Oxidative metabolism is used in low intensity/ long duration exercise, such as endurance races. Muscular glycogen depletion occurs slower than during anaerobic exercise because of the higher ATP output needed under anaerobic circumstances. Because of the availability of fatty acids as energy source, the horse can continue its exercise after glycogen depletion, but a decrease in performance is seen (Clayton, 1991).

\section{INFLUENCE OF TRAINING ON MUSCLE FUNCTION}

The aim of training is to improve sport performance and prevent the occurrence of training related injuries. Biochemically, depending on the type of applied training, either an increase in aerobic or anaerobic capacity occurs. Depending on the type of applied training, five important muscle fiber features can be influenced: 1. muscle morphometrics (vol- ume), 2. fiber type composition (transition), 3. muscle mitochondrial density, 4. muscular capillarization, 5. muscular enzymatic activity. There are three possible responses:

- Quantitative response: is an increase in muscle fiber volume, but with the same physiological and biochemical structures (hypertrophy).

- Qualitative response: is a transition in muscle fiber type, i.e. a change in structure and composition of the muscle fibers without changes in volume (remodeling) (Rivero, 2007).

- A combination of both.

Muscles undergo morphological adaptations in response to exercise. Fiber hypertrophy is typically seen after power training and is characterized by an increase in muscle diameter, with increased protein synthesis that leads to 'powerful muscles' with a decrease of the aerobic capacity (Clayton, 1991). Hypertrophy of IIx muscle fibers is unusual compared to type I fibers that already show hypertrophy in answer to low intensity power training. Type IIa fibers increase in volume mostly in response to high intensity/ short duration training. Endurance training typically increases the muscular capillarization. The capillary density may increase or decrease depending on the type of training. The circulation is particularly important during aerobic metabolism. Aerobic metabolism can mature with training due to an increase in the amount of mitochondria and enzymatic activity (Shoubridge, 1995; Lindner, 2011). Training probably also increases the amount of myofibrils per $\mu \mathrm{m}^{2}$ inside the muscle, i.e. it induces hyperplasia; however, there is only one equine study available reporting on the subject (Lindner, 2011). In that study, the number of myofibrils per $\mu \mathrm{m}^{2}$ decreased after conditioning, but increased again after the resting period. This was accompanied by a hypertrophy of the myofibrils after conditioning.

\section{ENERGY SUPPLY AND ENZYMATIC ACTI- VITY IN EXERCISING MUSCLES}

The enzymatic activity in muscles is a parameter for evaluating muscular function. Several enzymes and proteins, which are pivotal for the different energy cycles that occur in muscles, are thought to be influenced by training:

- Glucose transporter 4 (GLUT4) is an insulindependent glucose transporter present on myocytes and thus important in the muscles' fuel supply. In two studies, the GLUT4 muscle content in horses increased because of training, but a higher glucose influx was not seen in all training groups (McCutcheon et al., 2002; Stewart-Hunt et al., 2010).

- Phosphofructokinase (PFK) catalyzes the first enzymatic step of the glycolysis that uses ATP to metabolize glucose. Even in well-trained horses, this enzyme still gradually increases after long duration/low intensity exercise (Serrano et al., 2000; Eto et al., 2004).

- Lactate dehydrogenase (LDH) catalyzes the sec- 


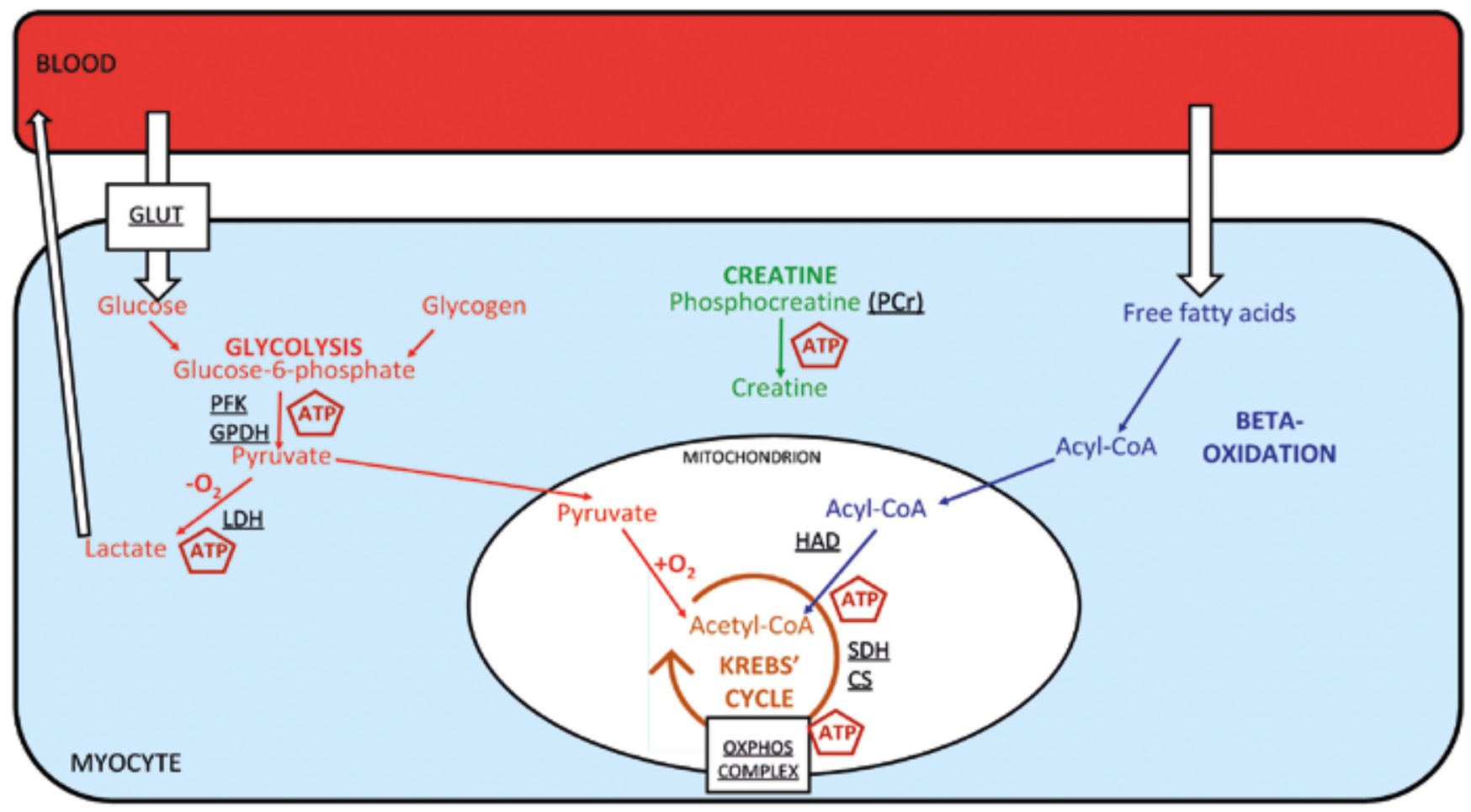

Figure 2. Fuel sources and energetic pathways in the myocyte. ATP is formed directly through glycolysis, phosphocreatine dephosphorylation and the Krebs cycle. NADH and FADH2 are energy-containing molecules formed during the glycolysis, Beta-oxidation and the Krebs cycle, and their energy is used during the oxidative phosphorylation in order to create ATP. The proteins/enzymes mentioned in the section 'Energy supply and enzymatic activity in exercising muscles' are underlined.

ond step of the glycolysis to produce ATP from the reaction from pyruvate to lactate. Training the horse decreases its lactic acid production, independently of the type of training (Serrano et al., 2000).

- Glycerol 3-phosphate dehydrogenase (GPDH) is the enzyme that pursues the glycolysis and brings the formed NADH to the mitochondria where oxidative phosphorylation takes place. This enzyme increases in equine type IIx fibers in answer to power training (Rivero et al., 2007).

- Succinyl dehydrogenase (SDH) is a key enzyme in the Krebs cycle to produce energy-rich molecules such as ATP from carbohydrates, as well as in the electron transportation chain during oxidative phosphorylation. High-intensity exercise might increase the activity of SDH (especially in type I fibers) (Rivero et al., 2007), but this increase has not been seen in trained horses subjected to exercise durations less than fifteen minutes (Eto et al., 2004).

- Citrate synthase (CS) is a marker for oxidative capacity and presence of intact mitochondria, and rises when the exercise duration increases (Serrano et al., 2000). CS transports acetyl-coA produced after fat metabolization ( $\beta$ oxidation) to the Krebs cycle where citric acid can be released.

- 3-Hydroxy-acyl-coA-dehydrogenase (HAD) is an oxidative marker and catalyzes the third step of the $\beta$ oxidation of fatty acids (Eto et al., 2004). As for CS, HAD activity increases after the implementation of low-intensity, long-duration exercise in horses (Ser- rano et al., 2000).

- Phosphocreatine (PCr) is a rapidly mobilizable reserve of high energy phosphate that donates a phosphate to adenosine-diphosphate (ADP) in order to create ATP. No effect of training on muscle $\mathrm{PCr}$ content has been demonstrated so far (Trilk et al., 2002).

- High resolution respirometry has also been applied in horses in order to determine the mitochondrial oxidative phosphorylation (OXPHOS) and electronic transport (ETS) capacity in muscle biopsies (Votion et al., 2010; Votion et al., 2012). These processes are conducted by a series of transmembranous enzymes (OXPHOS complex) in order to form ATP. The required energy is donated by $\mathrm{FADH}_{2}$ (reduced flavin adenine dinucleotide) and NADH (reduced nicotinamide adenine dinucleotide) that are derived from glycolysis, beta-oxidation and the Krebs cycle. Aerobic (endurance) training increases OXPHOS and ETS capacity in horses (Votion et al., 2010).

\section{FIBER TYPE TRANSITION}

The modification of muscular fiber type occurs because of changes in structure and enzymatic features of the transitional myocytes. After a high-intensity training period in untrained Thoroughbreds, an increase in IIx fibers has been noticeable (Yamano et al., 2002). In another study, a short period of highintensity training in already trained horses did not 
Table 2. Overview of the effect of different types of training on the aforementioned muscle parameters.

\begin{tabular}{|c|c|c|c|}
\hline \multirow[t]{2}{*}{ Parameter } & \multicolumn{3}{|c|}{ Type of training } \\
\hline & $\begin{array}{l}\text { High intensity, } \\
\text { short duration }\end{array}$ & $\begin{array}{l}\text { Intermediate intensity- } \\
\text { duration }\end{array}$ & $\begin{array}{l}\text { Low intensity, } \\
\text { long duration }\end{array}$ \\
\hline \multicolumn{4}{|l|}{ Morphological adaptations } \\
\hline Hypertrophy & Increase IIX $\geq$ IIA $>$ I & Increase IIA $>$ I $>$ IIX & Increase I $>$ IIA $>>$ IIX \\
\hline Capillaries & Increase & Increase & Increase \\
\hline Mitochondria & Increase & Increase & Increase IIA = IIX > I \\
\hline Nuclear density myocytes & Constant & Decrease & Decrease \\
\hline \multicolumn{4}{|c|}{ Chemical/metabolic adaptations } \\
\hline \multicolumn{4}{|l|}{ (An)aerobic activity } \\
\hline Vo2max & Increase & Increase & Increase \\
\hline Vla4 & Increase & Increase & Increase \\
\hline \multicolumn{4}{|l|}{ Energy supply } \\
\hline Glucose & No results found & No results found & No results found \\
\hline Glycogen & No conclusions to be drawn & No conclusions to be drawn & Increase in muscular content \\
\hline Fats & No results found & Constant & No results found \\
\hline $\begin{array}{l}\text { Lactic acid production } \\
\text { during exercise (LDH) }\end{array}$ & Decrease & Decrease & No results found \\
\hline SDH activity & Increase IIX $>$ IIA $>$ I & No conclusions to be drawn & No conclusions to be drawn \\
\hline GPDH activity & Increase in IIX type & No results found & No results found \\
\hline PFK activity & Increase & Decrease & Decrease \\
\hline CS activity & No results found & Increase & Increase \\
\hline PCr activity & No results found & Constant & No results found \\
\hline HAD activity & Constant & Increase & Increase \\
\hline OXPHOS activity & No results found & No results found & Increase \\
\hline GLUT4 content & No results found & Increase & No results found \\
\hline \multicolumn{4}{|l|}{ Fiber typing } \\
\hline Switch in muscle fiber type & I $>$ IIA $>$ IIX & No results found & IIX $>$ IIA $>$ I \\
\hline IIA/IIX ratio & Increase ++ & Increase + & No results found \\
\hline I/IIA ratio & No results found & Increase & Increase \\
\hline
\end{tabular}

induce perceptible changes in muscle fiber type (Eto et al., 2004). Ratios between fiber types can be calculated and compared over time to evaluate exerciseinduced fiber type transition. Several equine studies have shown that the IIa/IIx ratio increases as a result of stamina training (Rivero et al., 2001; Rivero, 2007; Serrano et al., 2000). Changes in this ratio are particularly intensity-dependent. When focusing on the effect of training on oxidative fibers, I/IIa ratio is used. It has been demonstrated that this ratio increases in answer to low-intensity endurance training in horses (Tyler et al., 1998).

EVALUATION OF THE PHYSIOLOGICAL MUSCULAR ADAPTATIONS DUE TO EXERCISE

When it comes to assessing the physiological adaptations that occur within the muscles of a horse due to training, several approaches are possible: 1 . followup of the evolution of performance parameters, such as speed, heart rate and blood lactic acid, throughout consecutive standardized exercise tests on a, for example, two-weekly basis, 2. follow-up of muscle morphometrics by means of ultrasound (Van de Winkel et al., 2016) 3. longitudinal follow-up of specific parameters, such as muscle fiber typing, total glycogen content, enzymatic activity, in serially harvested muscle biopsies.

Blood lactic acid is a reliable and easily measurable parameter to evaluate fitness in horses (Gansen et al., 1999; Eaton, 1999; Lindner, 2000). Blood is taken from the jugular vein and lactic acid is measured with a hand-held analyzer. Although blood lactic acid concentration is mentioned in the context of muscle physiology, it should be emphasized that blood lactic acid concentrations during exercise not only depend on muscle function but also on the cardiopulmonary system, as an adequate supply of oxygen towards the muscles is required for aerobic glycolysis and beta-oxidation. At rest, the lactic acid concentration in venous blood is below $1 \mathrm{mmol} /$ liter. Lactic acid concentration in blood increases when the intensity 
of exercise increases. Lactic acid is produced inside the muscle during anaerobic glycolysis. The physiological answer of the exercising body trying to prevent accumulation of lactic acid, is the Cori cycle. This cycle uses blood lactic acid to produce glucose inside the liver (gluconeogenesis). The freshly synthesized glucose is then released in the blood stream and thus available as energy source for the muscles. However, this so-called Cori cycle isn't beneficial from an energy point of view, as the gluconeogenesis requires more ATP than the ATP obtained during anaerobic glycolysis. When the production of lactic acid exceeds the capacity of the Cori cycle, a rise of lactic acid in blood will be observed. A blood lactic acid concentration of $4 \mathrm{mmol} /$ liter is traditionally considered to be the anaerobic threshold in both human and equine athletes. However, this value is rather arbitrary. From that moment onwards, the lactic acid levels rise exponentially with exercise, and muscles will fatigue. Incremental exercise tests, where the horse runs at increasing speeds for three to five minutes each in order to create a certain 'plateau' in effort, can be used to determine the velocity (Vla4) at which the horse reaches the blood lactic acid threshold of $4 \mathrm{mmol} /$ liter. Training the horse increases Vla4 and thus delays fatigue (Wasserman et al., 1973; Clayton, 1991; Rivero, 2007).

Another approach is the longitudinal follow-up of changes in muscle morphometrics. For example, eight weeks of aqua-training causes hypertrophy of specific muscles in the forelimb, back and hindlimb, particularly muscles involved in elevation and forward movement of the forelimb (e.g. m. brachiocephalicus), flexion of the hindlimb (e.g. m. quadriceps femoris vastus lateralis) and muscles used for extension of the spine (e.g. thoracal part of $\mathrm{m}$. erector spinae (Van de Winkel et al., 2016).

Finally, serial harvesting of muscle biopsies for example at the start and at the end of a training period and the subsequent analysis of a certain set of parameters may provide a lot of insight into the physiological adaptations that have occurred inside that muscle in response to a certain type of training protocol. As mentioned previously, in order to be able to compare results between studies, it is of crucial importance that the same set of muscles is biopsied at the same depth.

\section{CONCLUSIONS}

The goal of training is to modulate muscular physiology according to the demands of the specific sport discipline. Many standardized studies have been performed in human athletes, mapping out the effect of different types of exercise and different durations of training on muscular physiology. These types of studies reveal valuable information, for example: which muscular changes are to be expected in answer to a certain type of training, and after which time interval should they occur. This information can aid in setting up more evidence-based training schedules in order to increase performance. In horses unfortunately, knowledge on the physiological muscular adaptations due to exercise is scattered. The aim of the current review is to provide a concise overview of what is known about the effects of training in horses up until now.

\section{REFERENCES}

Buford T., Kreider R., Stout J., Greenwood M., Campbell B., Spano M., Ziegenfuss T., Lopez H., Landis J., Antonio J. (2007). International Society of Sports Nutrition position stand: creatine supplementation and exercise. Journal of the International Society of Sports Nutrition 4,6 .

Clayton H. (1991). Conditioning Sporthorses, Sport Horse Publications. Mason, first edition p 46-60.

Eaton M., Hodgson D., Evans D., Rose R. (1999). Effects of low-and moderate-intensity training on metabolic responses te exercise in Thoroughbreds. Equine Veterinary Journal 30, 521-527.

Eto D., Yamano S., Mukai K., Sugiura T., Nasu T., Tokuriki M., Miyata H.. (2004). Effect of high intensity training on anaerobic capacity of middle gluteal muscle in Thoroughbred horses, Research in Veterinary Science 76, 139-144.

Gansen S., Lindner A., Marx S., Mosen H., Sallmann H. (1999), Effects of conditioning horses with lactate-guided exercise on muscle glycogen content. Equine Veterinary Journal 30, 329-331.

Kawai M., Minami Y., Sayama Y., Kuwano A., Hiraga A., Miyata H. (2009). Muscle fiber population and biochemical properties of whole body muscles in Thoroughbred horses. The Anatomical Record 292, 1663-1669.

Lindner A. (2000). Use of blood biochemistry for positive performance diagnosis of sport horses in practice. Revue Médecine Vétérinaire 15, 611-618.

Lindner A., Dag Erginsoy S., Kissenbeck S. Mosen H., Hetzel U., Drommer W., Chamizo V.E., Rivero J.L. (2013). Effect of different blood-guided conditioning programmes on skeletal muscle ultrastructure an histochemistry of sport horses. Journal of Animal Physiology and Animal Nutrition 97, 374-386.

Lopez-Rivero J.L., Serrano A.L., Diz A.M., Galisteo AM. (1992). Variability of muscle fibre composition and fibre size in the horse gluteus medius: An enzyme-histochemical and morphometric study. Journal of Anatomy 181, $1-10$.

MacDougall J., Ward G., Sale D., Sutton J. (1977). Biochemical adaptation of human skeletal muscle to heavy resistance training and immobilization. Journal of Applied Physiology 43, 700-703.

McCutcheon L.J., Geor R.J., Hinchcliff K.W. (2002). Changes in skeletal muscle GLUT4 content and muscle membrane glucose transport following 6 weeks of exercise training. Equine Veterinary Journal. Supplement 34, 199-204.

Rivero J., Serrano A., Quiroz-Rothe E., Aguilera-Tejero E. (2001). Coordinated changes of kinematics and muscle fibre properties with prolonged endurance training, Equine Veterinary Journal, 33, 104-108.

Rivero J., Barrey E. (2001). Heritabilities and genetic and phenotypic parameters for gluteus medius muscle fibre 
type composition, fibre size and capillaries in purebred Spanish horses. Livestock Production Science 72, 233241.

Rivero J. (2007). A scientific background for skeletal muscle conditioning in equine practice. Journal of Veterinary Medicine 54, 321-332.

Rivero J., Ruz A., Martí-Korff S., Estepa JC., AguileraTejero E., Werkman J., Sobotta M., Lindner A. (2007). Effects of intensity and duration of exercise on muscular responses to training of thoroughbred racehorses, Journal of Applied Physiology 102, 1871-1882.

Rivero J., Hill E. (2016). Skeletal muscle adaptations and muscle genomics of performance horses. Equine Veterinary Journal 209, 5-13.

Schuback K., Essen-Gustavsson B., Persson S. (2000). Effect of creatine supplementation on muscle metabolic response to a maximal treadmill exercise test in Standardbred horses. Equine Veterinary Journal 32, 533-540.

Serrano A., Rivero J. (2000). Myosin heavy chain profile of equine Gluteus medius muscle following prolonged draught-exercise training and detraining, Journal of Muscle Research and Cell Motility 21, 235-245.

Shoubridge E. (1995). Segregation of mitochondrial DNAs carrying a pathogenic mutation (tRNAleu3243) in cybrid cells. Biochemy Biophysiology Research Communication 213, 189-195.

Snow D., Valberg S. (1994). Muscle anatomy, physiology and adaptations to exercise and training. In: Hodgson, D. and Rose R. (editors). The Atletic horse: Principles and Practice of Equine Sports Medicine, 145-179.

Stewart-Hunt L., Pratt-Phillips S., McCutcheon LJ., Geor RJ. (2010). Dietary energy source and physical conditioning affect insulin sensitivity and skeletal muscle glucose metabolism in horses. Equine Veterinary Journal (Supplement) 38, 355-360.

Trilk J., Lindner A., Greene H., Alberghina D., Wickler S. (2002). A lactate-guided conditioning programme to improve endurance performance. Equine Veterinary Journal 34, 122-125.

Tyler C., Golland L., Evans D., Hodgson D., Rose R. (1998). Skeletal muscle adaptations to prolonged training, overtraining and detraining in horses, Pflügers Archives - European Journal Physiology 436, 391-397.

Van de Winkel D., de Bruijn M., Touwen N., Duchateau L., Goethals K., Oosterlinck M., Pille F., Vanderperren K., Delesalle C., (2016). Morphometric changes in 15 skeletal muscles of horses after 8 weeks of aquatraining, Equine Veterinary Journal 48, 30-49.

Wasserman K., Whipp B., Koyal S., Beaver W. (1973). Anaerobic threshold and respiratory

gas exchange during exercise. Journal of Applied Physio$\log y$ 35, 236-243.

Yamano S., Eto D., Sugiura T., Kai M., Hiraga A., Tokuriki M., Miyata H. (2002). Effect of growth and training on muscle adaptation in Thoroughbred horses. American Journal of Veterinary Research 63, 1408-1412. 